\title{
Judging Social Behavior and Level of Intelligence Changes as a Result of Team Sport Training
}

\author{
Dr. Berliana, M.Pd \\ Indonesian University Of Education \\ Faculty Of Sport Health and Education \\ Coaching Education \\ Bandung, Indonesia \\ berliana.rahely@yahoo.co.id
}

\author{
Ira Purnamasari, M.Pd \\ Indonesian University Of Education \\ Faculty Of Sport Health and Education \\ Coaching Education \\ Bandung , Indonesia
}

\begin{abstract}
This study aimed to investigate whether athletes in team sports (football) who have been training for a long time, had social behavior changes. In this research ,a behavioral shift is the most important factor, because family, school, and sports club are expected to foster children's social behavior. This study also takes into account intelligence factor, because an extensive training program could improve children's level of intelligence. the Research method used in this research is a descriptive method. the Population used is football athletes from SME-UPI, who formed PS.UPI team in preparation for 2016 SSL championship (super soccer league) which account for 20 people in total. the Sample used the entire population, i.e. 20 people, employing the approach of total samples. Instruments used to gather data in the field consist of, a. social behavior questionnaire, $b$. football tactical test, and $c$. IQ tests (carried out by an authorized person, psychologist). The results of this study indicate that a. Social behavior of athletes in team sports who had an extensive amount of practice showed a significant correlation with the technical skills to play football , and $b$. The intelligence level of athletes in team sports who had an extensive amount of practice showed a significant correlation with the technical skills to play soccer. The recommendations proposed in this study is that social attitudes are formed through training, is also heavily dependent on the level of social behavior and intelligence, therefore it's advised that talent screening (talent scouting) on sports team should also measure social behavior and level of intelligence of the prospective athletes.
\end{abstract}

Key words: social behavior, team sports, intelligence

\section{INTRODUCTION}

In the process of team sports training, football for instance, exercise programs have already included psychomotor abilities, cognitive and affective training, meaning that there's collaboration of exercise during process, Goldstein [1] this three components are interrelated and interdependent.

Kid and teenager's social behavior have been very concerning recently, rampant brawl, cruel treatment, seems to be a common show in the media. Many factors that may trigger this, such as; leisure time is not utilized properly. It's also a result of non-synchronization between families, schools, and government who should've accommodated those kid's aspirations. Sport training venues (Sports clubs) are essentially a place to spend free time with positive activities. Through a long process, kids will get trained that develop their achievement and personality. We provide empirical evidence that social interaction ties positively affect volunteer attitudes and behaviors. More specifically, team member exchange and future intentions were significantly impacted by volunteers' social interaction on social media. The research results indicate several important theoretical implications. [2]

Football is a very popular public sport, evidenced by almost $100 \%$ of children in an early age love to play ball. Other than just as a game, there's one main characteristic that children must have, which is a healthy social behavior, so that during the game, athlete is able to demonstrate a high sportsmanship and do not believe that the end justifies the means. Although the spirit of playing to win should be maintained, but a positive behavior must also be preserved. For example, how to intercept the ball with not intentionally harming the opponent, to protest the referee in polite way, ending the match with no commotion, etc.

In addition to having good social behavior, football players are also expected to have good intelligence, evidenced by athletes is required to be able to take decisions in a short amount of time. As an example; when to pass the ball, to whom the ball will be passed, using which leg to pass the ball, what to do after passing the ball, where all this little steps will be continuously performed during the game, until it's time to shoot, and so on

In essence, this study is important, with the hope to improve the existing state of affairs as football games often perceived do not play according to the epitome of sportsmanship.

\section{PROBLEMS}

The problems that will be highlighted in this study is related to the process of football training, which not only emphasizes the physical development, but will also take into cognitive and affective development. All three must evolve simultaneously. For this reason all three variables was revealed all at once in this study with regards to football tactics (psychomotor), social behavior (affective), and intelligence (cognitive). Focus of the problems revealed in the research questions, as follows;

1. Does social behavior has a significant correlation with a player's tactical ability in the game of football?

2. Does IQ (intelligence quotient) had a significant association with the player's tactical ability in the game of football? 


\section{OBJECTIVE}

1. To find out whether social behavior has a significant relationship with a player's tactical ability in the game of football?

2. To find out whether IQ (intelligence quotient) has a significant association with the player's tactical ability in the game of football?

\section{THEORY}

Football is a team sport, meaning it's an activity in which individuals are organized into teams which compete to win, with the rules and regulations in place. During match, the meaning of pleasure and freedom are revealed, as expressed by, Explained Gleave and Hamilton [3] Play is a process that is freely chosen, personally directed and intrinsically motivated. That is, children and young people determine and control the content and intent of Reviews their play, by following Reviews their own instincts, ideas and interests, in their own way for Reviews their own reasons. All children and young people need to play. The impulse to play is innate. Play is a biological, psychological and social necessity, and is fundamental to the healthy development and well being of individuals and communities.

Participating in a team sport (football), can directly hone behavioral and intellectual abilities of children, as stated Nespeca [4] "Play is vital for early learning. It is not " recess " or a " timeout " from learning, rather it is the way young children learn. While playing, children learn about Reviews their world, acquire skills, Necessary for critical thinking, discover how to solve problems, and develop self - confidence. Play encourages healthy brain development while fostering exploration skills, language skills, social skills, physical skills and creativity.

Provisional conclusion can be drawn, that play, is a very significant facility in an effort to improve the child's ability, either physical abilities, cognitive, and affective. Goldstein elaborate the benefits of play, as follows:

Emotional-behavioral benefits of play

- Play reduces fear, anxiety, stress, irritability

- Creates joy, intimacy, self-esteem and mastery not based on other's loss of esteem

- Improves emotional flexibility and openness

- Increases calmness, resilience and adaptability and ability to deal with surprise and change

- Play can heal emotional pain.

Social benefits of play

- Increases empathy, compassion, and sharing

- Creates options and choices

- Models relationships based on inclusion rather than exclusion

- Improves nonverbal skills

- Increases attention and attachment

Physical benefits

- Positive emotions increase the efficiency of immune, endocrine, and cardiovascular systems

- Decreases stress, fatigue, injury, and depression
- Increases range of motion, agility, coordination, balance, flexibility, and fine and gross motor exploration

\section{METHODS}

Research method used to capture social behavior and intelligence issues at team sports (football) is the descriptive research methods. The population used in this study is PS.UPI team which account for 20 people. The reasons for selecting the population is, PS.UPI team is an organization that can serve as an example of successful football coaching in UPI with a lot of achievement in various championships at national level. Sample used in this study is the PS.UPI team of 20 people. The approach employed to determine the sample is total sampling. Instrument used to collect the data are, a. IQ test to measure intelligence test, using APM test (Advanced Progressive Metrics), b. questionnaire to measure social behavior, and c. observation sheet to measure players tactical abilities, which facilitates observer to assess the ability of the players to understand the tactics of the game. Referees act as assessors, who have national certificates, which were 3 people, and gave scores in the column provided on the observation sheet, according to players tactical performance in the field. The study design is as follows As for the research design used by the author is as follows

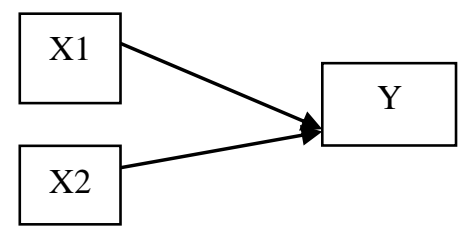

$\mathrm{X} 1$ : Social Behavior

X2 : Intelligence Quotient (IQ)

$\mathrm{Y}$ : Football Tactical Test (25 test items)

VI. DATA

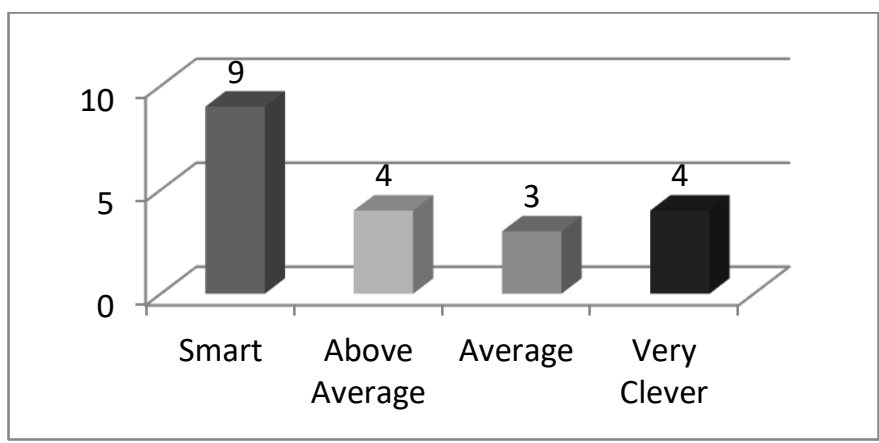

Fig 1. IQ Respondent, $\mathrm{n}=20$

The following display in the form of a diagram, item test tactical play the ball of the foot. As below 


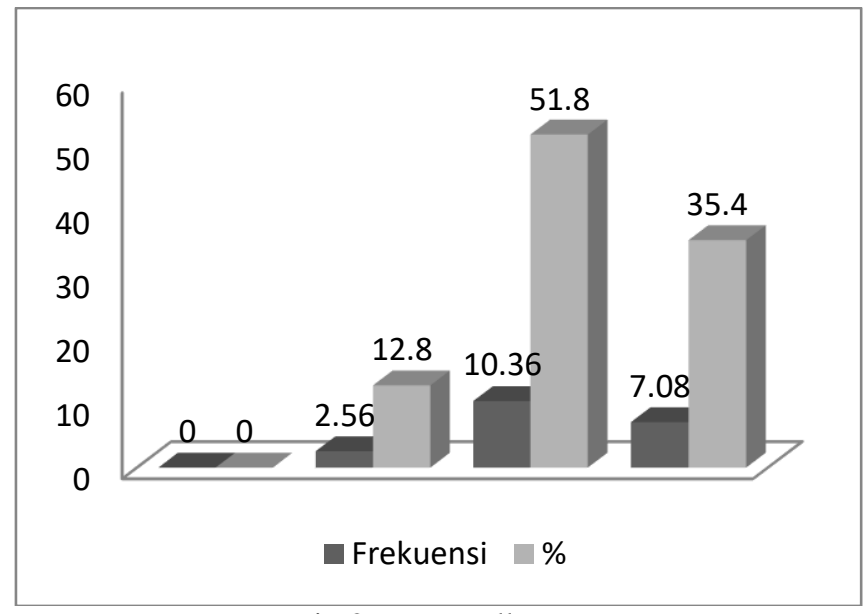

Fig 2. Foot Ball Test

Table 1. Correlation

\begin{tabular}{|rc|r|r|}
\hline & & \multicolumn{1}{|c|}{ IQ } & \multicolumn{2}{|c|}{ ability } \\
\hline IQ & Pearson Correlation & 1 & $0.969^{* *}$ \\
& Sig. (2-tailed) & & 0.000 \\
& $\mathrm{~N}$ & 20 & 20 \\
\hline ability & Pearson Correlation & $0.969^{* *}$ & 1 \\
& Sig. (2-tailed) & 0.000 & \\
$\mathrm{~N}$ & 20 & 20 \\
\hline
\end{tabular}

Pearson IQ and Football Tactical Skills Correlations Test Results **. Correlation is significant at the 0.01 level (2-tailed).

\begin{tabular}{|c|c|r|r|}
\hline & & VAR00001 & VAR00002 \\
\hline VAR00001 & Pearson & 1 & 0.191 \\
& Correlation & & 0.419 \\
& Sig. (2-tailed) & & 20 \\
& $\mathrm{~N}$ & 20 & 1 \\
\hline VAR00002 & Pearson & 0.191 & \\
& Correlation & 0.419 & 20 \\
& Sig. (2-tailed) & 20 & 2 \\
& $\mathrm{~N}$ &
\end{tabular}

Pearson Social Behavior and Football Tactical Skills Correlations Test Results

**. Correlation is significant at the 0.01 level (2-tailed).

\section{CONCLUSION}

1. There is a significant relationship between Social Behavior with the tactical skill of the soccer player.

2. There is a significant correlation between IQ (intelligence quotient) and the ability to perform tactical skills among soccer players.

\section{RECOMMENDATIONS}

The recommendations proposed in this study is that prospective football athletes are advised to take IQ tests and questionnaires of social behavior as a complementary instrument.

\section{CLOSING}

Team sports game, such as football, is very popular, because children can devote their energy and way to play. According to Goldstein (2012 pp., 6) "Play is essential to development because it contributes to the cognitive, physical, social, and emotional well-being of children and youth. Play also offers an ideal opportunity for parents to engage fully with Reviews their children ". Goldstein explains that the benefits of playing that is very important for growth, in terms of cognitive, psychomotor, social, and emotional. Therefore, parents are expected to lead their children to spend their free time exercising, especially team sports games.

Intelligence is an important aspect in this game, which is seen in the playing patterns and tactical skill. One of aspect were reflected by the speed of the athletes making a decision in directing the ball, passing the ball, and other activities in the field. Thus intelligence variables are chosen in this study.

Similar with social behavior, children will experience changes in social behaviors during the training process, because good manners are instilled throughout training process (effective upbringing). Thus both variables are also important to be investigated.

\section{REFERENCES}

[1] Goldstein, F. (2012). Play In Children's Development, Health And Well-Being. Toy Industries Of Europe (Tie). Boulevard De Waterloo: Brussels.

[2] Lee,Y.,etal.,(2016)

Theimpactofsocialinteractionandteammemberexchangeonsport event volunteermanagement.Sport ManagementReview. http://dx.doi.org/10.1016/j.smr.2016.04.005

[3] Gleave. J \& Hamilton, Issy C. (2012). A World Without Play.A Literature Review on The Effects of A Lack of Play on Children's Lives.Playengland.Org.Uk

[4] Nespeca, S. M. (2012).The Importance Of Play, Particularly Constructive Play, In Public Library Programming. 